\title{
Gender, Gender Role Identity, and Children's Reported Feelings Toward the Same and Opposite Sex ${ }^{1}$
}

\author{
Leslie R. Brody ${ }^{2}$ \\ Boston University \\ Deborah H. Hay \\ University of Saskatchewan \\ Elizabeth Vandewater \\ University of Michigan
}

The present study explored the relative importance of gender role identity, gender role attitudes, and biological gender in determining the intensity of anger, disgust, hurt, envy, fear, pity, and liking reported toward same- and opposite-sex children. Sixty male and 60 female 6-12-year-old children reported on the intensity of emotions that a hypothetical child would experience toward same- and opposite-sex children in various situations. The Children's Personal Attitudes Questionnaire, the Children's Attitudes toward Women Scale, and a self-reported toy preference measure were used to assess gender role identity and attitudes. The results indicated that girls were more angry at males than at females, and that both sexes tended to be more hurt and disgusted by opposite-sex than by same-sex children. Girls also tended to report more fear than did boys, and both sexes tended to report more fear of males than of females. Most importantly, gender role identity and attitudes accounted for more of the variance in predicting the quality of reported emotions than did biological gender. Biological gender predicted to only one feeling: pity toward males, after the variance accounted for by the gender

\footnotetext{
'This research was supported by a Gender Roles Grant from the Rockefeller Foundation. We are grateful for their support. The authors wish to thank the parents, teachers, and children in the Milton, Norwood, and Watertown school systems, and especially Frank Guiliano, Rod Smith, and Daniel O'Connor. We are also grateful for the computer and statistical expertise of Robert H. Harrison, John Houlihan, and Lance S. Davidow, and for the editorial comments made by Robert $\mathrm{H}$. Harrison.

${ }^{2}$ To whom correspondence should be addressed at the Psychology Department, Boston University, 64 Cunningham Street, Boston, MA 02215.
} 
role traits was removed. In general, both boys and girls who scored highly on feminine gender role identity were both communal and vulnerable in their reported emotions (high in reported liking, fear, and hurt). Children's reported feelings toward the same- and opposite-sex children seemed to be based on the evaluation of whether other children's biological gender differed from the children's own gender role identity characteristics.

Several researchers and theoreticians have pointed out the importance of exploring the associations between gender role identity and attitude variables and other personality variables in both males and females, e.g., the relations between masculine and feminine gender role characteristics and self-reported emotions in both males and females. The exploration of these relations would enable us to better understand and interpret sex differences in the personality variables of interest (Brody, 1985; Hall \& Halberstadt, 1981; Wallston, 1981). For example, if females are found to report less anger than males, do males with feminine gender role characteristics also report less anger than do other males? If so, this would indicate that it is the personality attributes differentially associated with males vs. females that underlie the sex differences in reported anger.

The focus of this paper is on the extent to which sex differences as well as within-sex variations in children's gender role identities and attitudes contribute to the quality of children's reported feelings toward the same and opposite sex. Much is known about the quality of boys' and girls' feelings about each other at different ages. For example, school-aged children have more positive feelings, including liking and warmth, toward peers of the same sex, and more negative feelings, including disgust and anger, toward peers of the opposite sex (Brody, 1987; Hayden-Thomson, Rubin, \& Hymel, 1987; Serbin, Tonick, \& Sternglanz, 1977). Both sexes report more fear in interactions with boys than in interactions with girls (Brody, 1987). Furthermore, affect research has indicated that girls report more intense feelings of fear toward both boys and girls than do boys (Eisenberg \& Lennon, 1983; Brody, 1985). Yet little is known about the personality differences (including individual differences in gender role identity) that are associated with such feelings.

Gender role identity is a multidimensional construct (cf. Huston, 1985), which can include both clusters of personal attitudes (Bem, 1974; Spence \& Helmreich, 1978) and gender-typed behaviors, for example, occupational choice and gender-typed toy preferences (Silvern \& Katz, 1986). When gender role identity is measured as clusters of personal attributes, the personality traits subsumed under the term "masculinity" may be thought of as socially desirable "agentic" or instrumental traits, and the cluster of traits subsumed under the term "femininity" as socially desirable "communal" or socioemotional traits (Hall \& Halberstadt, 1981). Gender role attitudes are defined 
as values and beliefs about the equality of women's and men's roles. Attitudes are included here for study because many studies suggest that children's cognitive judgments and attitudes greatly affect their emotional reactions to others, and ultimately, their behavior (Dodge \& Somberg, 1987). Some studies have suggested that gender role attitudes are related to gender role identity personality traits (cf. Hall, 1978).

There is some evidence to suggest that gender role attitudes and identity may be equal in importance to, if not more important than, biological gender in mediating the quality of children's feelings. For example, studies using the Profile of Nonverbal Sensitivity (PONs) to assess nonverbal emotional recognition skills (Rosenthal, Hall, DiMatteo, Rogers, \& Archer, 1979) indicate that although females are generally better at decoding and attending to affective cues than are males (Hall, 1976, 1978; Rosenthal \& DePaulo, 1979), gender role identity is also a powerful predictor of these skills. Using a toy preference measure, Hall (1976) found that a tendency for liking girls' games was associated with lower scores on the PONs (i.e., poorer nonverbal decoding skills). Similarly, Hall and Halberstadt (1981), using selfreport measures of gender role identity, found that more masculine gender role identity in both sexes tended to predict better decoding ability. However, Hall (1976) found that for both sexes, the more concordant gender role was with biological gender, the more sensitive the children were to nonverbal emotional cues. The inconsistent results across these studies may be due to age differences in the samples or to measurement differences. Nonetheless, they suggest that gender-typed personality traits may be an important mediator in understanding children's emotional responses. For example, it may be that feelings of fear are experienced more by both boys and girls with a feminine gender role identity than by children with a masculine gender role identity. A feminine gender role identity in both sexes may be associated with status and power, and hence with feelings such as fear and envy (cf. Kemper, 1978).

Attitudes toward gender role may also be important in determining children's emotions toward the same and opposite sex, since the extent to which children endorse traditional attitudes about male and female roles has been found to be related to their gender role identity and to their nonverbal emotional sensitivity. Hall (1976) found a general tendency for self-report of femininity in children of both sexes to be associated with profeminist attitudes. In addition, profeminist attitudes among girls and more traditional attitudes among boys related to higher sensitivity to nonverbal affective cues. Somewhat inconsistently, Spence and Helmreich (1978) found that more conservative attitudes toward women's roles were related to higher masculinity among adult men and higher femininity among adult women. Again, as with the research relating gender role identity to emotional functioning, these data may be inconsistent because of age differences in the samples, cohort differences, or measurement differences. For example, the relations among gender 
role identity, attitudes, and emotional functioning may vary at different ages, thus producing inconsistent patterns across studies. Nonetheless, the data suggest that gender role attitudes may be related to children's feelings toward the same and opposite sex. For example, both boys and girls with profeminist attitudes may be more angry at males than those with more traditional attitudes.

We set out to investigate the relative contributions made by biological gender, gender role identity, and gender role attitudes toward the intensity of children's reported feelings about their same- and opposite-sex peers. More specifically, we asked whether biological gender, gender role identity, or gender role attitudes accounted for more of the variance in the intensity of children's reported feelings. For example, do girls with a masculine gender role identity like boys more than do both boys and girls with a feminine gender role identity? Seven emotions (anger, disgust, hurt, fear, envy, pity, and liking) were selected based on social and interpersonal theories of emotion (Kemper, 1978; Lewis, 1985) as well as the peer preference literature cited above (Hayden-Thomson et al., 1987). Social and interpersonal theories of emotion suggest that females, as a lower status group, should feel anger, envy, fear, and hurt toward males, a higher status group. Males, as a higher status and power group, should feel disgust and pity toward females. The peer preference literature suggests that both sexes should have more positive feelings (liking) toward the same sex and more negative feelings (anger and disgust) toward the opposite sex.

Our research also attempted to address the limitations in previous research by controlling for the effects of social desirability on children's selfreported emotions and by treating gender role identity as a multidimensional construct, including several domains such as personality attributes, attitudes, and toy preferences. Other researchers have noted the importance of addressing both of these issues (cf. Crandall, Crandall, \& Katkovsky, 1965; Huston, 1985).

We selected two age groups based on literature about the development of children's gender role stereotypes: a group of children whose average age was $7 \frac{1}{2}$ years; and a group of children whose average age was $11 \frac{1 / 2}{2}$ years. Children in the younger age group have been found to have more rigid gender role stereotypes than those in the older group (Williams, Bennett, \& Best, 1975).

\section{METHOD}

\section{Subjects}

One hundred twenty children participated in the study: 30 female ( $M$ age $=7.45$ years, $S D=.66$ years, range $=6.17-8.50$ years) and 30 male 
( $M$ age $=7.62, S D=.66$ years, range $=6.17-8.58$ years $)$ first and second genders, and 30 female $(M$ age $=11.51, S D=.60$, range $=10.31-12.45$ years) and 30 male ( $M$ age $=11.65, S D=.71$, range $=10.00-12.91$ years) fifth and sixth graders. Across the sample, the average age for girls was 9.48 years, $S D=2.16$; for boys it was 9.59 years, $S D=2.25$. Children were drawn from 12 suburban schools in the greater Boston geographical area whose population was predominantly white. Socioeconomic status, as measured by fathers' occupation on the Hollingshead-Redlich scale (HollingsheadRedlich, 1958) varied from 2 (semiskilled) to 7 (major professional), with a median of 4.34 (clerical/administrative). Children received toy prizes for their participation.

\section{Procedure}

Children were individually tested at their schools by female examiners on two different occasions. The two testing sessions were separated by at least 24 hours ( $M$ interval $=8.49, S D=7.27$ days; range $=1-27$ days). The length of the delay between testing sessions did not correlate significantly with scores on any of our dependent measures. Each session lasted approximately 45 minutes.

The data for this study were collected as part of a larger project on emotional development in children and families. Only those measures of interest to the present study will be discussed here. During the first session, the following measures were administered: the first half of the Emotional Story Task, the Children's Personal Attitudes Questionnaire (Hall \& Halberstadt, 1980) and the Children's Attitudes Toward Women Scale (Hall, 1976). During the second session, the second half of the Emotional Story task and the Children's Social Desirability Questionnaire (Crandall, Crandall, \& Katkovsky, 1965) were administered. After each session, children were asked to specify gender-typed toy preferences in choosing their prizes, as described below.

\section{Measures}

Emotional Story Task. The semiprojective Emotional Story Task consisted of 24 stories representing eight different types of situations. Four of the situations depicted characters in gender-typed behaviors, including female and male socially desirable and undesirable behaviors, and four of the situations depicted characters in emotionally laden, gender role neutral situations evoking the feelings of anger, fear, envy, and warmth. There were three different stories depicting each of the eight different types of situations. Female-stereotyped undesirable behaviors were represented by three 
stories that portrayed instrumentally incompetent, weak, and passive behaviors; male-stereotyped undesirable behaviors were represented by three stories that portrayed bossy, rough, and teasing behaviors; female-stereotyped desirable behaviors were represented by three stories that portrayed neat, nurturant, and gentle behaviors; and male-stereotyped desirable behaviors were represented by three stories that portrayed adventurous, brave, and strong behaviors. One story depicted each of the above characteristics. There were also three different gender role neutral stories depicting each of four types of emotionally laden situations (written to evoke anger, envy, fear, and warmth) in which the behavior of the story character was gender role neutral, e.g., walking. To summarize: there were eight different situations presented, depicting four gender role neutral situations (anger, envy, fear, and warmth), and four gender-typed situations (female socially desirable, male socially desirable, female socially undesirable, and male socially undesirable behaviors). There were 3 different stories written to depict each of these eight situations, resulting in 24 stories in total. In all stories, it was the story character who provoked the intended emotion, e.g., anger, fear, envy. Examples of stories used are shown in Table I.

Stories were developed through pilot testing on 20 children (aged 6-12) and 20 adults. Potential stories were given to pilot subjects with a genderneutral story protagonist " $X$," and subjects were asked to decide whether the character was male or female and to list the emotions the story depicted. Stories were selected for use in the task if $75 \%$ of the subjects agreed on the feeling depicted by the story (for affect-laden stories) or agreed that the behavior was sex typed (for gender-typed stories).

The entire set of 24 stories was administered to each child twice, once with a male and once with a female character. The order in which male vs. female story characters was presented was counterbalanced within Age $\times$ Sex groups. In order to minimize socially desirable responses, the task was made more projective, and children were not asked about how they themselves would feel about the story character, but rather female subjects were asked how a girl named Mary would feel, while male subjects were asked how a boy named John would feel about the story character. Thus, children were always asked about how a same-sexed child would feel toward both male and female story characters. Children were shown a picture of the story while it was being told. Pictures were line drawings in which characters could be construed as either boys or girls and had no facial features. (For each story, the same picture was used for male and female protagonists.)

After the interviewer read each story aloud, she asked the child about the intensity of seven different feelings. Emotions were queried as follows: Anger: Would Mary/John feel mad at ? Disgust: Would Mary/John feel that____ is a yukky kid? Envy: Would Mary/John wish that s/he 
Table I. Sample Stories Used

Gender Role Stereotyped Stories

Female socially desirable: This child takes care of his/her friends when they're not feeling well. S/he tries to make them feel better and cheer them up, and hugs them to let them know that $\mathrm{s} /$ he likes them. (nurturant)

Female socially undesirable: This child wishes that $\mathrm{s} / \mathrm{he}$ could build a model plane, but s/he can't figure out how to do it. S/he can't get the pieces to fit together right. (instrumentally incompetent)

Male socially desirable: This child is really strong. $\mathrm{S} /$ he has really big arm muscles, and if anyone asks her to carry something heavy, it's really easy for her/him to do it. (strong)

Male socially undesirable: This child likes to tumble around a lot and to play rough games, and sometimes hits and kicks other kids in a game. S/he also sometimes breaks toys because $\mathrm{s} / \mathrm{he}$ plays with them in such a rough way. (rough)

\section{Gender Role Neutral Stories}

Fear: John/Mary is playing alone in his/her room at night and suddenly notices that a strange boy/girl is outside his window and is watching him/her. S/he doesn't know what the boy/girl is going to do next.

Envy: This child always gets lots of money to buy candy bars and sodas and Mary/John never does.

Liking/respect: This child made a lemonade stand and sells lots of lemonade. S/he wants to give the money to help poor people.

Anger: John/Mary just built the best sandcastle that s/he ever made. This child walked along the beach and purposely stepped on it.

could be (brave) like because s/he's not so (brave)? Fear: Would Mary/John be scared of __ ? Hurt: Would Mary/John's feelings be hurt by ___ Pity: Would Mary/John feel sorry for ___ ? Warmth/respect: Would Mary/John like____ and feel that s/he was a good person? If children said yes to any of the questions, they were asked whether they would feel that way a little, some, or a lot, thus generating a 4-point scale: no, $a$ little, some, or a lot. The order of questions was randomized across stories.

Interviewers discussed the seven feelings with the children before starting the task to ensure that they understood the feelings that were being described. Drawings of facial expressions depicting the three different intensities of each emotion were shown to the children. Four 6-year-old boys were not included in the study because they did not understand the emotions "sorry for" or "hurt by," and could not make a distinction between the two.

For each sex, 14 alpha reliability coefficients were calculated, one for each of the emotions reported toward males and toward females. For each emotion, the intensities of the feeling reported in each of the 24 story situations were used as the 24 items in the reliability analysis. For boys, the coeffi- 
cients ranged from .68 (for pity toward males) to .89 (for respect toward females) with a mean across the 14 coefficients of .80 . For girls, the coefficients ranged from .75 (for envy of females) to .87 (for disgust toward males), with a mean across the 14 coefficients of .82 . Thus, there was substantial consistency in the intensity of each emotion reported toward males and females across different situations.

Children's Social Desirability Questionnaire (CSDQ). Children's tendencies to give socially desirable responses were assessed using a modified version of the CSDQ (Crandall et al., 1965). The CSDQ is a 48 item true-false inventory that is read aloud to each child. The items concern typical childhood activities such as wishing to play instead of going to school, as well as statements concerning feelings. Originally, the CSDQ was developed for use with children 8-18 years of age. We simplified the vocabulary in some of the items in order to make them more comprehensible for the younger age group we were testing, and we also reduced the length of the scale to 26 items. High split-half and test-retest reliabilities, and both convergent and discriminant validity, for the original scale have been reported (Crandall et al., 1965; Tomlinson-Keasey \& Klieger, 1974). The alpha reliability coefficient for our 26-item scale was .82.

Gender Role Identity. Many researchers have argued for a multidimensional approach to measuring gender role identity (Silvern \& Katz, 1986; Huston, 1985; Katz \& Boswell, 1984). Research has indicated that the various gender role domains (i.e., personality traits, toy preferences, occupational choices) are not highly correlated, and that each domain addresses a different aspect of the construct. It is for this reason that we chose to include two measures of gender role identity in the present study - one a selfreport trait measure (Children's Personal Attributes Questionnaire) and one a self-labeled toy preference measure (whether the child reported preferring masculine or feminine types of toys). Each measure is described below.

Children's Personal Attributes Questionnaire (CPAQ). This measure is the children's form of the Personal Attributes Questionnaire (PAQ; Spence, Helmreich, \& Stapp, 1974), a widely used measure of adult gender roles. The CPAQ was originally developed by Hall (1976) in her dissertation work, was subsequently revised by Hall and Halberstadt (1980), and has been used since in other studies of gender differences (cf. Silvern \& Katz, 1986; Huston, 1985). The measure used in the present study is a minimally modified version of the CPAQ short form, originally a 21 -item questionnaire. Our version consisted of 18 of the original bipolar items describing personal characteristics, each rated on a 4-point scale. Unlike the administration used in earlier versions, we read each item aloud to each child. There are three 6-item scales: (1) a masculinity scale ( $M$ scale), consisting of male-stereotyped traits that 
are socially desirable in both sexes (e.g., leadership); (2) a femininity scale (F scale), consisting of female-stereotyped traits that are socially desirable in both sexes (e.g., kindness); and (3) a masculinity-femininity scale (MF scale), consisting of traits that are socially more acceptable for one sex or the other (e.g., emotional vulnerability and aggressiveness). High scores on the MF scale indicate tendencies toward aggressive, and/or emotionally invulnerable behavior. Several construct validity studies (including discriminant and concurrent validity studies) using both the short and long forms of the CPAQ have shown that the scales differentiate boys from girls (Katz \& Boswell, 1984), are related to children's self-concept (Hall \& Halberstadt, 1980) and school adjustment (Silvern \& Katz, 1986), and are not related to cognitive ability or to teacher ratings of social competence (Hall \& Halberstadt, 1980). Both the internal consistency and the retest reliability of each scale have been found to be high (Hall \& Halberstadt, 1980).

As discussed in detail below, in our sample the CPAQ differentiated boys from girls on the $\mathrm{M}$ and MF scales, and the $\mathrm{F}$ scale correlated with more profeminist attitudes on the Children's Attitudes toward Women Scale. Alpha reliability coefficients computed on the three scales were .74 for the $F$ scale, .46 for the M scale, and .02 for the MF scale. Because of its low reliability, the MF scale was eliminated from some of the analyses testing the major hypotheses of interest to the present study. Although the alpha reliability for the $\mathrm{M}$ scale was lower than might be expected, the low item intercorrelations in no way negate the substantive findings discussed below. The alpha coefficient simply indicates that the $M$ scale is measuring a multidimensional construct, as has been demonstrated in factor analytic studies of the $M$ and $F$ scales using the adult PAQ (cf. Gerber, 1988).

In order to further assess the concurrent validity of the revised CPAQ, we also asked parents to fill out an identical written measure on their child. A subsample of parents complied with our request (42 mothers and 46 fathers). Mothers' and fathers' ratings were significantly correlated for each of the three scales: $M$ scale: $r=.45, p<.01$; F scale: $r=.60, p<.001$; MF scale: $r=.58, p<.001$. Because the mothers' and fathers' scores were so highly correlated, we averaged them to form one parent rating. There was a significant correlation between parents' ratings of masculinity and boys' ratings of their own masculinity $(r=.57, p<.01)$ as well as a positive but nonsignificant correlation between parents' ratings of femininity and boys' ratings of their own feminity $(r=.26, p>.10)$. These relationships for girls were not significant (for masculinity, $r=-.19$; for femininity, $r=$ $-.18)$. On the MF scale, there were positive but nonsignificant correlations for both boys and girls (for girls: $r=.26, p>.10$; for boys: $r=.36 ; p$ $<.10$ ). When the same correlations were examined partialling out children's 
social desirability scores, the only result that was substantially different was that the correlation between boys' own ratings of their femininity and parents' ratings of boys' femininity became stronger $(r=.36, p<.10)$.

In interpreting what parents' ratings of their children's gender role identity might reflect, it is interesting that $t$ tests indicate that mothers rate their children higher on femininity $(M=14.83, S D=2.76)$ than do fathers [M $=13.49, S D=3.26 ; t(41)=2.06, p<.05$ ]. Differences between mothers and fathers on the $M$ and the MF scales were not significant (mothers: $M$ scores: $M=12.07, S D=2.76$; MF scores: $M=7.32, S D=2.44$; fathers: M scores: $M=11.93, S D=3.57$; MF scores: $M=7.58, S D=2.59$ ). It is not clear whether mothers rate their children more highly for feminine characteristics because they tend to value behavior that is consistent with their own gender role identity or because children tend to act more feminine around mothers and less feminine around fathers (cf. Hall, 1976).

The correlations between parents' and children's CPAQ scores suggest that the two are somewhat related, especially for boys. In other words, boys' ratings of their gender role traits seem to reflect characteristics that are observable to both self and others. In contrast, girls' self-reports on the CPAQ seem to be their own perceptions of their gender role personality attributes. We did not include parent ratings in subsequent analyses involving the CPAQ because of the relatively low number of parents who responded to this measure.

Self-Labeled Gender-Typed Toy Preference Measure. Following each of the two testing sessions, children received a toy prize. Before being allowed to view the prizes [which were different each time, but always included a variety of toys that were gender stereotypic (cars, jewelry) as well as gender neutral (pens, notepads)], children were asked whether they wanted a prize that was for boys, for girls, or for both boys and girls. Thus, our measure consisted of three categories: children who said they wanted a toy appropriate for girls, children who said they wanted a toy appropriate for boys, and children who said they wanted a toy appropriate for both sexes. Our toy preference measure avoided many of the problems inherent in procedures in which adults designate in advance the sex-typed nature of toys and interests (cf. Huston, 1985), and allowed us to maintain a shorter protocol.

Children's Attitudes Toward Women Scale (CAWS). Children's gender role attitudes were measured using a modified version of the CAWS developed by Hall (1976), and originally developed from a similar scale for adults, the Attitudes Toward Women Scale (Spence \& Helmreich, 1972). The CAWS is a 12-item true-false inventory that assesses the extent to which children endorse traditional attitudes about male and female roles. For example, children are asked if they agree or disagree with statements like "It is more important for a boy to go to college than a girl." Each statement is rated on 
a 4-point scale ranging from really true to really false. Hall's original measure was designed for use with older children. Several modifications were necessary to make the scale more comprehensible to younger children, including simplifying the vocabulary and rewording all responses in a positive set, e.g., rather than "using bad words is worse for a girl than it is for a boy," we asked, "it's more okay for boys to use bad words than for girls." The resulting scale consisted of 8 items. For half of the items "really true" represented a "profeminist" attitude, while for the other half "really false" represented a "profeminist" attitude, with these two types of items randomly ordered. Adequate reliability and construct validity for the original scale has been reported by Hall (1976). The alpha reliability coefficint for the revised scale was .72 .

\section{RESULTS}

\section{Preliminary Analyses}

Relationships Between Scores on the CSDQ and Other Measures. CSDQ scores ranged from 2 to 24 out of a possible total of 26 , with high scores indicating greater tendencies toward socially desirable behaviors. As displayed in Table II, scores on the CSDQ correlated significantly with many of the other measures in the study. For both boys and girls it was socially desirable to score highly on femininity and not socially desirable to score highly on masculinity and masculinity-femininity. Correlations for each sex separately were in the same direction as for the entire sample.

The CAWS was significantly negatively correlated with the CSDQ Scale for the sample as a whole, but when the correlations for each sex were ex-

Table II. Correlations Between CSDQ Scores and CAWS, CPAQ, and Toy Preference Scores

\begin{tabular}{lccc}
\hline & \multicolumn{3}{c}{ Children's social desirability scores } \\
\cline { 2 - 4 } & $\begin{array}{c}\text { Girls } \\
(n=60)\end{array}$ & $\begin{array}{c}\text { Boys } \\
(n=60)\end{array}$ & $\begin{array}{c}\text { Entire sample } \\
(n=120)\end{array}$ \\
\hline CPAQ & & & \\
M scores & $-.29^{c}$ & -.12 & $-.19^{c}$ \\
F scores & .25 & $.31^{c}$ & $.27^{d}$ \\
MF scores & -.18 & $-.26^{c}$ & $-.21^{c}$ \\
CAWS $^{a}$ & -.23 & -.16 & $-.19^{c}$ \\
Toy preference $^{b}$ & .05 & -.08 & .03 \\
\hline
\end{tabular}

${ }^{a}$ High scores mean more profeminist attitudes.

${ }^{b}$ High scores mean more masculine toy preferences.

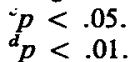


Table III. Correlations of Emotional Attributions with Social Desirability Scores

\begin{tabular}{lclc}
\hline Emotion & CSDQ & Emotion & CSDQ \\
\hline Anger toward males & $-.23^{b}$ & Anger toward females & $-.24^{c}$ \\
Disgust toward males & $-.33^{d}$ & Disgust toward females & $-.35^{d}$ \\
Envy toward males & -.12 & Envy toward females & -.01 \\
Fear toward males & $-.31^{d}$ & Fear toward females & $-.26^{c}$ \\
Hurt toward males & -.16 & Hurt toward females & -.15 \\
Pity toward males & $-.18^{b}$ & Pity toward females & -.09 \\
Warmth toward males & $.20^{b}$ & Warmth toward females & $.32^{d}$ \\
\hline
\end{tabular}

${ }^{a}$ All correlations are two-tailed Pearson $r$ tests.

${ }^{b} p<.05$.

$\begin{aligned}{ }^{c} p & <.01 \\ d p & <.001\end{aligned}$

plored separately, the results were not significant for either sex. Toy preference scores did not significantly correlate with CSDQ scores for either sex or for the sample as a whole.

Preliminary analyses also revealed that CSDQ scores were significantly negatively correlated with the average intensity of anger, disgust, fear, and pity, and significantly positively correlated with the average intensity of liking reported toward male and female protagonists. These correlations are displayed in Table III. Because of the significance of so many of these correlations, as well as because social desirability scores were correlated with scores on the CPAQ and with CAWS scores as reported above, the variance contributed by CSDQ scores was controlled for in all of the analyses discussed next.

Age and Sex Effects on the CPAQ. The CPAQ was scored on a 0-18-point scale for each of the three scales: the $M$ scale, the $F$ scale, and the MF scale. Each child received three independent scores on the three scales. Analyses were done using continuous scores on these scales. When the three scales were tested for significant relations using two-tailed partial correlations (controlling for social desirability), the results revealed that for both girls and for the sample as a whole, $\mathrm{M}$ and $\mathrm{F}$ scales were significantly correlated (girls: $r=.32, p<.05$; entire sample: $r=.22, p<.05$; boys: $r$ $=.19, p>.05$ ). There were no other significant correlations among the three scales.

Two (age) $\times 2$ (sex) analyses of covariance (ANCOVAs), using social desirability scores as the covariate, revealed that boys scored higher on the $M$ and MF scales than did girls [main effect for sex: $M$ scale: $F(1,115)=$ 8.33, $p<.005$; boys' $M=8.50, S D=2.84$; girls' $M=6.87, S D=3.39$; MF scale: $F(1,115)=4.03, p<.05$; boys' $M=7.58, S D=2.71$; girls' $M=6.64, S D=2.44]$. There were no sex or age differences or interactions on the F scale (boys' $M=11.61, S D=3.80$; girls' $M=12.38, S D$ $=3.44$; means are adjusted for the effects of social desirability). 
Table IV. Partial Correlations Between the Attitudes Toward Women Scale and the CPAQ Gender Role Identity Scales

\begin{tabular}{lcrc}
\hline & Girls & \multicolumn{1}{c}{ Boys } & Entire sample \\
\hline F scale & $.30^{a}$ & .16 & $.23^{a}$ \\
M scale & .21 & -.17 & -.01 \\
MF scale & .10 & -.01 & .02 \\
\hline${ }^{a} p<.05$. & & &
\end{tabular}

Age and Sex Effects on the CAWS and Relations with Other Measures. Partial correlations (partialling out social desirability scores) between the CAWS and the F, M, and MF scales of the CPAQ are displayed in Table IV. These results revealed that feminine gender role identity (higher F score) was correlated with more profeminist attitudes in both girls and in the sample as a whole. Two (age) $\times$ (sex) ANCOVAs on CAWS scores, using CSDQ scores as a covariate, revealed that younger children were more traditional in their attitudes toward women's roles than were older children $[\mathrm{F}$ age $(1,116)$ $=36.53, p<.001 ; M$ for older children $=20.19, S D=2.37$; $M$ for younger children $=16.24, S D=4.34$ ], but no main effects for sex or Sex $\times$ Age interactions were revealed.

Relations Between Toy Preference Scores and Other Scores. Children's responses were coded on a 5-point scale, ranging from feminine toy preferences (1) to masculine toy preferences (5). Children were coded (1) if they asked for a girl's toy both times, (2) if they asked for a girls' toy once and a toy appropriate for both sexes once, (3) if they asked for a toy appropriate for both sexes twice, (4) if they asked for a boys' toy once and a toy appropriate for both sexes once, and (5) if they asked for boys' toys twice. No child asked for a girls' toy once and a boys' toy once; hence the scoring system does not reflect that category. Twenty-five girls and no boys obtained scores of 1,18 girls and no boys obtained scores of 2,15 girls and 10 boys obtained scores of 3, two girls and 17 boys obtained scores of 4 , and 31 boys and no girls obtained scores of 5 . (Data are missing for 2 boys because the examiner neglected to ask the child's toy preference.) A 2 (age) $\times 2$ (sex) ANCOVA, with CSDQ scores as the covariate, revealed a significant main effect for $\operatorname{sex}[F(1,114)=178.78, p<.001]$ with girls scoring more feminine [or less masculine $(M=1.90, S D=.91)$ ] in toy preference than boys scored $(M=4.36, S D=.77)$. Neither the age effect nor the Age $\times$ Sex interaction were significant. [Because of the uneven sex distribution in each cateogry, an alternative scoring system was generated that divided children into one of two categories: either feminine in toy preference or masculine in toy preference. The first category included girls who said that they wanted a girl's toy both times they were asked, and boys who said that they want- 
ed toys for both boys and girls at least one of the two times they were asked (children who preferred feminine toys). The second category included boys who said they wanted toys for boys both times they were asked, and girls who said they wanted a toy for both boys and girls (or boys only) at least one of the two times they were asked (children who preferred masculine toys). We felt that children would need to ask for the toys of their own sex at least twice in order to be considered as identifying with their own sex, whereas children who asked for a toy that was appropriate for both sexes or for the opposite sex at least once should be considered as identifying with the opposite sex. In this coding system 11 younger girls and 14 older girls said they would prefer girls' toys in both sessions. These girls were categorized as feminine in toy preference. Nineteen younger and 16 older girls said they would prefer nonsame-sex typed toys across both sessions (i.e., either a toy for both boys and girls, or a toy for boys in one session and for girls in another). These latter girls were categorized as masculine in toy preference. Fifteen younger and 16 older boys said they would prefer boys' toys in both sessions (masculine toy preference); while 14 younger and 13 older boys said they would prefer nonsame-sex typed toys (feminine toy preference). All subsequent analyses involving toy preference were performed twice: once using the scoring system described here and once using the scoring system described above. The two sets of analyses yielded identical results, with the exception of the regression analysis predicting to the average fear reported toward females, which is described on p. 380 . The original 5-point scoring system is the one referred to in all toy preference analyses described below.

When boys and girls were looked at separately, scores on the toy preference measure did not significantly correlate with scores on the CAWs, nor with scores on the M, F, or MF scales of the CPAQ, using partial correlations in which the variance contributed by CSDQ scores was controlled. When correlations for the entire sample were explored, MF scores did significantly correlate with a tendency toward masculine toy preference scores $(r(118)=$ $.23, p<.05$ ). We thought that this might be because boys scored more highly than girls on both measures. In fact, when gender was partialled out of the correlation, the correlation between MF scores and toy preference scores became non-significant $(r 118)=.15)$. These results suggest that measures of gender role identity using toy preference and those using personality traits are independent.

Scoring of the Emotional Story Task. For the purposes of the present study, we were interested in the relationships among gender, gender role identity, attitudes toward gender roles, and reported emotions across different types of emotionally laden situations. For this reason, we chose to average the intensity (scores ranged from 0 to 4 ) of each of the seven emotions reported toward male and female protagonists, collapsing across all of the 24 stories 
presented. This led to 14 outcome variables: the average intensity of each of the seven emotions reported toward male protagonists and the average intensity of the seven emotions reported toward female protagonists. We did not analyze the effects of type of situation in this study (e.g., male and female undesirable and desirable situations). We also did not analyze the story task for age effects in this study because those analyses were reported at length elsewhere (Brody, 1987). Thus, in the analyses reported below, the two ages were grouped together.

\section{Analyses}

Gender Differences in Reported Emotions. A 2 (sex) $\times 2$ (sex of protagonist) multivariate analysis of covariance was performed with social desirability scores as a covariate using the seven emotions as dependent measures. The multivariate main effect for sex tended toward significance $[F(7,111)$ $=1.80, p=.09]$, with univariate $F$ tests revealing a significant sex difference for fear $[F(1,111)=5.59, p=.02]$. because this multivariate $F$ value across emotions was not significant, the univariate results for fear should be interpreted cautiously. Nonetheless, the univariate results strongly suggest that the average intensity of fear reported by girls was more than that reported by boys ( $M$ for girls: $.55, S D=.25 ; M$ for boys: $.43, S D=$ .28]. Similarly, the multivariate main effect for protagonist was not significant $[F(7,112)=1.72, p=.11]$, but the univariate $F$ value for fear was highly significant $[F(1,112)=9.01, p<.005]$. The means revealed that males were scarier $(X=.52, S D=.27)$ than were females $(X=.47, S D=.28)$ to both sexes. The multivariate sex by protagonist interaction was significant $[F(7,112)=2.30, p<.05]$, with univariate $F$ values for anger $[F(7,112)$ $=4.14, p<.05]$ and disgust $[F(7,112)=4.40, p<.05]$ being significant and with hurt tending toward significance $[F(7,112)=3.27, p=.07]$. Means for boys and girls for anger, hurt, and disgust are displayed in Table V. Post

Table V. Means and Standard Deviations for Anger, Disgust, and Hurt Toward Males and Females

\begin{tabular}{|c|c|c|c|c|c|c|}
\hline & \multicolumn{2}{|c|}{ Anger } & \multicolumn{2}{|c|}{ Disgust } & \multicolumn{2}{|c|}{ Hurt } \\
\hline & Males & Females & Males & Females & Males & Females \\
\hline \multicolumn{7}{|l|}{ Boys } \\
\hline$M$ & .85 & .86 & .67 & .71 & .75 & .78 \\
\hline$S D$ & .28 & .31 & .36 & .36 & .31 & .39 \\
\hline \multicolumn{7}{|l|}{ Girls } \\
\hline$M$ & .91 & .85 & .71 & .67 & .81 & .76 \\
\hline$S D$ & .33 & .31 & .37 & .37 & .35 & .38 \\
\hline
\end{tabular}


hoc Newman-Keuls analyses on the means for these emotions revealed that girls were angrier at males than were boys. Girls were also angrier at males than they were at females, whereas boys were equally angry at males and at females. Although the Newman-Keuls analyses for disgust and hurt were not significant, inspection of the means indicated a tendency for each sex to be more disgusted at and hurt by the opposite sex than by the same sex.

Relations Among Gender, Gender Role Variables, and Reported Emotions. Two types of analyses were performed in order to test the relations among gender, gender role identity, and attitudes and emotions toward the same and opposite sex. The first set of analyses were partial correlations between each of the gender role variables (M, F, CAWs, and toy preferences scores) and the emotion variables for boys and girls. Social desirability scores were partialled out of these correlations. The results of these analyses are displayed in Table VI. The results indicate that for girls, high masculinity and high femininity scores were significantly related to more intense disgust reported toward both males and females. High masculinity scores significantly related toward anger reported toward females and envy reported toward males. In contrast, high femininity scores were significantly related to more intense anger reported toward males. More feminine toy preferences correlated with more fear and hurt reported toward males. For boys, high masculinity scores were related to more intense envy reported toward males and females, more intense feelings of hurt reported toward females, and more intense liking reported toward males. High femininity scores in boys were related to more intense envy, fear, hurt, and liking reported toward both males and females. Boys who were more feminine in toy preference also reported more intense pity toward males than did boys who were less feminine in toy preference. Children's attitudes toward women's roles did not correlate significantly with any of the emotion variables for either sex.

The patterns inherent in these results will be discussed fully below, and certainty indicate that the gender role identity variables are systematically related to the pattern of emotion reported toward the same and opposite sex in both boys and girls.

Gender Role Identity and Attitudes vs. Biological Gender. In order to test whether biological gender, gender role identity or gender role attitudes accounted for more of the variance in the quality of children's reported emotions, two sets of stepwise multiple regression analyses were run for the sample as a whole. Each set consisted of 14 analyses in which the outcome variable was the average intensity of each of the seven emotions reported toward males and toward females. In each set of analyses the predictor variables were social desirability scores, biological gender, CPAQ M scores, CPAQ F scores, CAWS scores, and toy preference scores. In all analyses, social desirability scores were forced into the equations as the first variable in order to control for the variance 
Table VI. Partial Correlations Between Gender Role Variables and Emotions for Each Sex

\begin{tabular}{|c|c|c|c|c|c|c|c|c|c|c|}
\hline & \multicolumn{2}{|c|}{ CPAQ F scale } & \multicolumn{2}{|c|}{ CPAQ M scale } & \multicolumn{2}{|c|}{ MF scale } & \multicolumn{2}{|c|}{ CAWS } & \multicolumn{2}{|c|}{ Toy preference } \\
\hline & Boys & Girls & Boys & Girls & Boys & Girls & Boys & Girls & Boys & Girls \\
\hline \multicolumn{11}{|l|}{ Anger } \\
\hline Males & .12 & $.28^{a}$ & .05 & .25 & -.02 & .04 & -.02 & .15 & -.18 & -.21 \\
\hline Females & .16 & .25 & .12 & $.33^{a}$ & -.11 & -.14 & .01 & .09 & -.04 & -.08 \\
\hline \multicolumn{11}{|l|}{ Disgust } \\
\hline Males & .19 & $.35^{a}$ & -.06 & $.46^{b}$ & .12 & .00 & .06 & .19 & .05 & -.16 \\
\hline Females & .08 & $.26^{a}$ & -.03 & $.41^{a}$ & -.04 & -.04 & .08 & .04 & .03 & -.12 \\
\hline \multicolumn{11}{|l|}{ Envy } \\
\hline Males & $.29^{a}$ & .20 & $.37^{a}$ & $.28^{a}$ & -.09 & .13 & -.11 & -.12 & -.10 & -.14 \\
\hline Females & $.30^{a}$ & -.02 & $.27^{a}$ & .25 & -.18 & .21 & -.10 & -.21 & -.13 & -.17 \\
\hline \multicolumn{11}{|l|}{ Fear } \\
\hline Males & $.27^{a}$ & .17 & .11 & .19 & -.03 & -.23 & .05 & .16 & -.15 & $-.32^{\alpha}$ \\
\hline Females & $.33^{a}$ & .17 & .07 & .20 & -.09 & -.14 & .13 & .04 & -.15 & $\ldots 18$ \\
\hline \multicolumn{11}{|l|}{ Hurt } \\
\hline Males & $.36^{a}$ & .17 & .14 & .19 & -.06 & -.10 & .00 & .09 & -.06 & $-.31^{\alpha}$ \\
\hline Females & $.37^{\alpha}$ & .05 & .30 & .18 & -.11 & -.10 & -.03 & -.07 & -.04 & -.23 \\
\hline \multicolumn{11}{|l|}{ Pity } \\
\hline Males & .20 & .15 & .08 & .00 & .00 & .02 & .01 & .16 & $-.28^{a}$ & -.20 \\
\hline Females & .21 & .14 & .21 & -.15 & -.04 & -.08 & -.18 & -.01 & -.24 & .05 \\
\hline \multicolumn{11}{|l|}{ Liking } \\
\hline Males & $.26^{a}$ & .21 & $.39^{a}$ & -.10 & -.17 & $.30^{\alpha}$ & -.12 & -.16 & -.18 & .06 \\
\hline Females & $.33^{a}$ & .08 & .16 & -.01 & -.25 & .25 & -.07 & -.09 & -.18 & .11 \\
\hline
\end{tabular}

$a p<.05$.

${ }^{b} p<.01$.

accounted for by the relations between social desirability scores and the outcome variables. In one of the two sets of analyses, biological gender was forced into the equations as the last variable; in the second set of analyses, it was forced into the equation as the first variable following social desirability scores. In other words, the gender role identity and gender role attitude variables were forced into the equations either before or after biological gender had been entered, and within that limitation each gender role variable was allowed to enter the equation according to the percent of variance that each accounted for. This procedure was followed in order to examine the unique variance (change in $R^{2}$ ) contributed by either biological gender or the gender role variables to the quality of children's emotional attributions.

The results of these analyses can be found in Table VII, which displays the change in $\boldsymbol{R}^{2}$ for each variable. The overall pattern of results indicates that gender role identity is a more powerful predictor of reported emotions than is biological gender. After the contribution of biological gender is accounted for, $M$ scale scores continued to predict to the average anger $(B=$ $.21)$, disgust $(B=.19)$, and hurt $(B=.19)$ reported toward females; and to the average envy reported toward both males $(B=.28)$ and females $(B$ 
Table VU. $R^{2}$ Changes in Predicting Emotions Reported Toward Males and Females from Biological Gender, Gender Role Identity, and Attitudes

\begin{tabular}{|c|c|c|c|c|c|}
\hline Emotions & $\begin{array}{c}\text { Biological } \\
\text { gender }\end{array}$ & $\begin{array}{l}\text { M scores } \\
\text { (CPAQ) }\end{array}$ & $\begin{array}{l}\text { F scores } \\
\text { (CPAQ) }\end{array}$ & $\begin{array}{c}\text { Toy } \\
\text { preference }\end{array}$ & $\begin{array}{c}\text { Gender } \\
\text { attitudes }\end{array}$ \\
\hline \multicolumn{6}{|l|}{ Anger } \\
\hline Males & .01 & .01 & $.04^{a}$ & $.04^{a}$ & .00 \\
\hline Females & .00 & $.05^{a}$ & .02 & .00 & .00 \\
\hline \multicolumn{6}{|l|}{ Disgust } \\
\hline Males & .00 & .03 & $.07^{b}$ & .00 & .00 \\
\hline Females & .00 & $.04^{a}$ & .01 & .00 & .00 \\
\hline \multicolumn{6}{|l|}{ Envy } \\
\hline Males & .00 & $.11^{c}$ & $.03^{\alpha}$ & .01 & .02 \\
\hline Females & .01 & $.07^{b}$ & .02 & .02 & .02 \\
\hline \multicolumn{6}{|l|}{ Fear } \\
\hline Males & .01 & .01 & $.05^{\alpha}$ & $.05^{a}$ & .00 \\
\hline Females & .00 & .00 & $.06^{a}$ & .02 & .00 \\
\hline \multicolumn{6}{|l|}{ Hurt } \\
\hline Males & .01 & .01 & $.07^{\alpha}$ & $.04^{a}$ & .00 \\
\hline Females & .01 & $.06^{a}$ & .03 & .02 & .01 \\
\hline \multicolumn{6}{|l|}{ Pity } \\
\hline Males & $.04^{a}$ & .00 & $.03^{a}$ & $.06^{a}$ & .00 \\
\hline Females & .02 & .00 & .03 & .01 & .02 \\
\hline \multicolumn{6}{|l|}{ Liking } \\
\hline Males & .00 & .00 & $.06^{b}$ & .00 & $.03^{a}$ \\
\hline Females & .00 & .00 & $.05^{a}$ & .00 & .01 \\
\hline
\end{tabular}

${ }^{a} p<.05$.

${ }^{b} p<.01$.

$c_{p}<.001$.

$=.24)$. F scale scores continued to predict to anger $(B=.18)$, disgust $(B$ $=.21)$, envy $(B=.23)$, hurt $(B=.25)$, fear $(B=.19)$, pity $(B=.17)$, and liking $(B=.28)$ reported toward males; and to fear $(B=.22)$ and liking $(B=.25)$ reported toward females. Feminine toy preference scores predicted to fear $(B=.37)$, hurt $(B=.35)$, pity $(B=.42)$, and anger $(B$ $=-.33$ ) reported toward males. More profeminist gender role attitudes predicted to less liking reported toward males $(B=-.18)$.

After the variance contributed by the gender role identity scores and attitude scores was accounted for, biological gender significantly increased the predictive power in only one analysis: the intensity of pity reported toward males $(B=.35)$. Regardless of their gender role identity, boys reported more intense pity toward other boys than did girls. [Biological gender also significantly predicted to the average fear reported toward females $(B=-.23)$ when the alternative toy preference scoring system was used that distributed boys and girls fairly evenly within masculine and feminine toy preferences. In this analysis, girls reported more fear of female protagonists than did boys, regardless of their gender role identity. However, it is felt that this analysis should carry less weight than the one reported earlier in the text because it 
forces an even distribution of the sexes into each toy preference category. In doing so, it is less reflective of the finding that boys and girls most often stated that they would prefer to play with toys appropriate for their own sex.]

\section{DISCUSSION}

Seven emotions reported toward the same and opposite sex were examined in this study, including anger, disgust, envy, fear, hurt, pity, and liking. Girls reported more intense anger toward males than toward females, whereas boys reported anger equally toward males and toward females. Both sexes tended to report more disgust and hurt toward the opposite sex than toward the same sex. These results confirm and expand previous work on children's peer preferences, which indicate more positive feelings toward samesex peers and more negative feelings toward opposite-sex peers (HaydenThomson et al., 1987).

Girls tended to report more intense fear than did boys, and both sexes tended to report more intense fear of males than of females. These results do not seem to support theories of emotion based on power and status differences between males and females (Kemper, 1978). Theories based on power and status differences would have predicted more intense fear, hurt, envy, and anger toward boys by girls, and more intense disgust and pity toward girls by boys. The finding that both boys and girls reported more fear of males than of females suggests instead that boys are scarier than are girls to both sexes, possibly because of their association with aggressive behaviors resulting in possible physical harm (Zalk \& Katz, 1978). Although both sexes are more intensely scared of boys, girls tend to report more intense fear toward both sexes. This may be because girls are typically socialized to be nonaggressive and passive (Block, 1979). They may feel even more vulnerable and less able to protect themselves from physical harm than do boys.

The argument that both boys and girls may be more scared of boys than of girls because they perceive boys to be aggressive was supported by informal interviews that followed the data collection. Children's reasons for being scared of boys included statements like "because boys can beat you up more than girls" (given by a 6-year-old boy), "because sometimes they're stronger than girls and they're bigger" (given by a 9-year-old boy), "because most girls are not too strong" (given by a 6-year-old girl), and "because by nature boys are more threatening and muscular and girls are kind of sweet" (given by a 10-year-old girl).

Perhaps the most important finding in the present study was the relatively minimal influence of biological gender and the relative importance of 
gender-related personality traits and toy preferences in determining emotions reported toward the same and opposite sex. After the variance contributed by biological gender was removed, gender role stereotypic traits and toy preferences significantly predicted to the intensity of all emotions reported by both boys and girls except pity toward females. In contrast, biological gender significantly predicted to only one emotion: pity toward males, after the variance determined by the gender role identity and attitude variables had been removed.

Both boys and girls with high feminine traits reported more intense fear and hurt toward both sexes, suggesting feelings of greater vulnerability. Social psychological theories predict such feelings to be typical of lower status and power groups, specifically females (Kemper, 1978; Lewis, 1985). In the present study, females did tend to report more fear than did males, but biological gender was less important in determining reported feelings of vulnerability than was the degree to which both sexes characterized themselves as having feminine-typed personality attributes, such as helpfulness and empathy. In the regression analyses, a higher feminine gender role identity on the CPAQ for both boys and girls was related to more intense reports of fear toward both males and females and reports of hurt by males. Feminine toy preferences also related to greater reports of fear toward and hurt by males. The correlations showed significant relations between CPAQ feminine traits and fear and hurt for boys, and conceptually similar relations between feminine toy preferences and reported feelings of fear and hurt for girls. It is probable that feminine traits were associated with more vulnerable feelings because of the lower power and assertiveness associated with feminine traits.

Regression analyses controlling for biological gender further indicated that feminine attributes related to reported liking of males and females. Once again, the correlations for each sex separately revealed that this was especially true for boys. For both boys and girls, the association between feminine traits and liking peers helps qualify social psychological theories of emotion, which predict that females should have warmer feelings toward others than should males, regardless of their gender role traits (cf. Lewis, 1985). These theories suggest that warmth and liking are adaptive for females because they facilitate group relationships, which may help minimize aggressive attacks (Brody, 1985) and because they may be adaptive for a childrearing role (Lewis, 1985). The results of this study indicated that females did not report more intense liking than did males, but rather that feminine characteristics in both boys and girls predicted to liking. When boys and girls are looked at separately, the relation between communal traits and liking (as well as fear and hurt) was actually stronger in boys than in girls, perhaps because there was less variance in feminine traits for girls than for boys.

The association between liking others and feminine traits may be due to the way in which feminine traits were defined and measured (Spence \& 
Helmreich, 1978). Post hoc partial correlations between individual items on the CPAQ femininity scale and reported liking revealed that two items on the F scale related significantly to reported liking of males and females: "I am a warm and friendly person" and "I try to help other people." It is not surprising that characteristics such as helpfulness and friendliness would correlate with reported liking of others. What remains interesting is that these results were not unique to girls, but held true for children of both sexes. Thus, any theory of emotion based on interpersonal or social roles, or on power and status differences between the two sexes (Kemper, 1978; Lewis, 1985), needs to consider the effects of gender role identity on emotion, not just biological gender.

In this sample, feminine traits were correlated with social desirability scores for both sexes, whereas masculine traits were not. These findings suggest that feminine traits have higher status in this age group than do masculine traits. The higher status of feminine traits may help explain why boys pitied males (for whom feminine traits are less stereotypically characteristic) more than did girls. The higher status of feminine traits may also help explain why boys with high feminine toy preference scores reported more intense pity toward males than did boys with low feminine toy preference scores. Research has certainly indicated the school-aged boys present more problems of an externalizing nature for their teacher and their parents than do sameaged girls (Achenbach \& McConaughy, 1987), and that both boys and girls associate boys with negative behaviors in school, including behaviors such as throwing papers on the floor, answering questions wrong, and having no friends (Zalk \& Katz, 1978). Perhaps because of these problems, boys, and especially boys with a feminine gender role identity, may feel sorry for other boys. It may be that girls do not feel the same degree of pity for boys because their reported feelings of anger, disgust, and hurt toward boys do not allow them to experience pity.

Interestingly, children's reported feelings about the same and opposite sex seemed to be based on an evaluation of whether other children's biological gender differed from the children's own gender role identity characteristics. The regression analyses indicated that both boys and girls tended to report feeling more angry at (and sometimes more hurt by, disgusted by, and pitying of) other children whose biological sex differed from their own gender role identity. For example, children with high $\mathbf{M}$ scale scores reported more anger, disgust, and hurt toward females (but not toward males), while high $\mathrm{F}$ scale scorers reported more anger, disgust, and pity toward males (but not toward females). The same finding was true for toy preference: feminine toy preference predicted to anger, fear, hurt, and pity reported toward males, 3but not toward females. Thus, children reported feeling more negatively about other children whose biological gender differed from their own gender role identity. The correlations for each sex separately were somewhat 
consistent with these results. A higher feminine gender role identity in girls significantly related to anger reported toward males, not females; whereas a masculine gender role identity significantly related to anger reported toward females, not males. (However, the pattern of the results for the correlations is not as strong as for the regressions: anger reported toward both males and females in girls tended to be higher with both higher masculine and feminine CPAQ scores, suggesting that girls with a firmer sense of their own identity report feeling more anger in general, as discussed more fully below.) Similarly, in boys, a masculine gender role identity related to hurt reported toward females, not males; whereas in girls, feminine toy preference related significantly to hurt toward males, not females. The finding that boys scoring highly on masculinity reported more intense liking of other boys, not girls, is also consistent with the idea that children evaluate their feelings by comparing their own gender role traits to the biological gender of hypothetical children. If the children's own gender role traits and the biological gender of the other children match, feelings will be positive; if they do not, feelings will be negative.

This pattern is consistent with Gnepp's findings that children draw on the personality attributes of characters to infer emotional reactions and behaviors (Gnepp \& Chilamkurti, 1988). The present study further indicates that children assume hypothetical peers have gender role personality traits consistent with biological gender, i.e., that all boys have male-stereotyped traits and all girls have female-stereotyped traits. (This may not be true of boys and girls with whom the children are familiar, since in the present study, the peers were all hypothetical.) Research on the development of gender role stereotypes certainly suggests that children's gender role stereotypes are pervasive and widely generalized (Williams, Bennett, \& Best, 1975). It may be that children's dislike of other children whom they assume to differ from themselves and warmth toward children whom they assume to be similar to themselves helps in the process of self-differentiation and self-esteem maintenance.

The results for envy were somewhat puzzling, and indicate that social psychological theories about envy between sexes (e.g., that girls envy boys for their high status or that children with female traits will envy those with male traits) are too simplistic. When biological gender was controlled for, children who scored more highly on male traits reported more intense envy toward both males and females, whereas those who scored more highly on female traits reported more intense envy only toward males. When each sex was looked at separately, boys who scored highly on both feminine and masculine traits reported high envy of both males and females, whereas girls who scored highly on masculine traits reported high envy of males (and also tended to report high envy of females). Girls' femininity scores did not significantly relate to envy of either sex. 
The relationships between envy reported toward both sexes and high $\mathbf{M}$ scores may indicate that high $\mathbf{M}$ scorers of this age group are more dissatisfied with themselves than are low $M$ scorers. This interpretation is supported by the present study's finding that for both boys and girls it was socially desirable to have feminine but not masculine characteristics on the CPAQ. Children with masculine characteristics (e.g., assertive, independent) may have particularly low status. Why, then, should boys with high femininity scores (which are socially desirable) envy both males and females? The answer is not clear from the present data. It may be that the self-esteem of boys who score highly on femininity is not as high as the social desirability of their characteristics would suggest, and that their envy of both sexes reflects a vulnerable self-esteem and a wish to be different. This hypothesis can be only speculative.

Correlations for each sex separately indicated that for girls, high scores on masculinity and femininity significantly related to reporting more disgust toward both males and females, and tended to relate to reporting more anger toward both males and females. Disgust and anger can both considered to be other-directed emotions, as opposed to inner-directed emotions such as sadness or hurt. Rather than reflecting vulnerability, they reflect a more active stance toward the other, the expression of which may engender retaliation, rejection, or abandonment by the other. The emotions of disgust and anger are typically associated with males (cf. Brody, 1985). Thus, it is interesting that girls with a firm sense of their own identity (whether that be masculine or feminine) are more likely to report such feelings. Perhaps a firm identity is associated with increased confidence to negatively evaluate peers, and with the ability to withstand potential rejection, hurt, and abandonment.

It is also noteworthy that this study corroborates other research in indicating that different gender role identity and attitude measures are not highly related, and supports the use of multimeasures of gender role identity. However, the patterns of relations among the gender role identity variables and the quality of self-reported emotions do suggest that the various gender role measures are assessing a similar construct. For example, femininity scores related to more feminist attitudes toward women's roles, suggesting that those children who have female gender-related traits are more sensitive to and supportive of equal rights for women. This is consistent with research done by Hall (1976), who found that self-report of femininity in both sexes was associated with profeminist attitudes. Furthermore, among both boys and girls, more profeminist attitudes predicted less liking of males, indicating that emotions and attitudes are linked. Children who support equal rights for women may like males less either because they view males as upholding the status quo (and thus hindering equal rights for women) and/or because they are nontraditional in both their attitudes and feelings toward males. Finally, 
although toy preference and self-reported gender role identity traits were not significantly correlated, they related to the quality of children's emotional reports in similar ways. Children scoring highly on femininity both on the CPAQ as well as on toy preference reported feeling more hurt by and angry at males.

It is important to note that the responses assessed by the gender role identity measures and the emotion story measures were quite distinct in content, i.e., a relationship between these measures is not predetermined because of similarities in what is being measured. For example, scoring highly on helpfulness and kindness on the CPAQ does not dictate that a child will also score highly on reported fear toward males on the story task. Furthermore, the relationship between gender role identity and quality of reported feelings often varied depending on which sex was the object of those feelings, with children scoring highly on masculine gender role identity feeling more negatively toward girls and those scoring highly on feminine gender role identity feeling more negatively toward boys. This gender specificity strongly argues against the possibility that the findings are due to children having a consistent response bias toward all measures.

In summary, the results of the present study indicate that many factors influence the quality of children's self-reported emotions, including their own gender role identity, biological gender, gender role attitudes, and the biological gender of the person about whom they are experiencing the feelings. Gender role identity was especially important in predicting the quality of emotions reported, and accounted for more of the variance in predicting the quality of emotions than did biological gender. Biological gender may continue to appear salient in other emotions research because, in this culture (and as indicated by some of our data), males continue to be more agentic than females, and females continue to be more communal than males. Thus, although gender role identity is a more powerful determinant of feelings than is biological gender, gender role identity is masked by biological gender when the two variables are not measured independently.

\section{REFERENCES}

Achenbach, T., \& McConaughy, S. (1987). Empirically based assessment of child and adolescent psychopathology, Newbury Park, CA: Sage Publications.

Bem, S. (1974). The measurement of psychological androgyny. Journal of Consulting and Clinical Psychology, 42, 155-162.

Block, J. H. (1979). Another look at sex differentiation in the socialization behavior of mothers and fathers. In J. Sherman \& F. L. Denmark (Eds.), Psychology of women: Future directions in research. New York: Psychological Dimensions.

Brody, L. R. (1985). Gender differences in emotional development: A review of theories and research. Journal of Personality, 53, 102-149. 
Brody, L. R. (1987). Both boys and girls are more scared of boys. Poster presented at the biannual meeting of the Society for Research in Child Development, Baltimore, MD.

Crandall, V. C., Crandall, V. J., \& Katkovsky, W. (1965). A children's social desirability questionnaire. Journal of Consulting Psychology, 29, 27-36.

Dodge, K., \& Somberg, D. (1987). Hostile attributional biases among aggressive boys are exacerbated under conditions of threats to the self. Child Development, 58, 213-224.

Eisenberg, N., \& Lennon, R. (1983). Sex differences in empathy and related capacities. Psychological Bulletin, 94, 100-131.

Gerber, G. L. (1988). Leadership roles and the gender stereotype traits. Sex Roles, 18, 649-666.

Gnepp, J., \& Chilamkurti, C. (1988). Children's use of personality attributions to predict other people's emotional and behavioral reactions. Child Development, 59, 743-754.

Hall, J. (1976). Sex-role related correlates of sensitivity to non-verbal cues. Unpublished doctoral dissertation, Harvard University.

Hall, J. (1978). Gender effects in decoding nonverbal cues. Psychological Bulletin, 85, 845-857.

Hall, J., \& Halberstadt, A. (1980). Masculinity and femininity in children: Development of the children's personal attributes questionnaire. Developmental Psychology, 16, 270-280.

Hall, J., \& Halberstadt, A. (1981). Sex roles and nonverbal communication skills. Sex Roles, $7,273-287$.

Hayden-Thomson, L., Rubin, K., \& Hymel, S. (1987). Sex preferences in sociometric choices. Developmental Psychology, 23, 558-562.

Hollingshead, A. B., \& Redlich, F. C. (1958). Social Class and Mental Illness. New York: Wiley.

Huston, A. (1985). The development of sex typing: Themes from recent research. Developmental Review 5, 1-17.

Katz, P., \& Boswell, S. L. (1984). Sex-role development and the one-child family. In T. Falbo (Ed.), The Single-child family. New York: The Guilford Press.

Kemper, T. (1978). A social interactional theory of emotions. New York: Wiley.

Lewis, H. B. (1985). Depression vs. paranoia: Why are there sex differences in mental illness? Journal of Personality, 53, 150-178.

Rosenthal, R., \& DePaulo, B. (1979). Sex differences in accommodation in nonverbal communication. In R. Rosenthal (Ed.). Skill in nonverbal communication. Cambridge, MA: Oelgeschlager, Gunn \& Hain.

Rosenthal, R., Hall, J., DiMatteo, M. R., Rogers, P. L., \& Archer, D. (1979). Sensitivity to nonverbal communication: The PONS test. Baltimore, MD: Johns Hopkins University Press.

Serbin, L. A., Tonick, I. J., \& Sternglanz, S. H. (1977). Shaping cooperative cross-sex play. Child Development, 48, 924-929.

Silvern, L., \& Katz, P. (1986). Gender roles and adjustment in elementary-school children: A multidimensional approach. Sex Roles, 14, 181-202.

Spence, J., \& Helmreich, R. (1972). The Attitudes toward Women Scale: An objective instrument to measure attitudes toward the rights and roles of women in contemporary society. Journal Supplement Abstract Service Catalog of Selected Documents in Psychology, 2, 66-67.

Spence, J., \& Helmreich, R. (1978). Masculinity and femininity: Their psychological dimensions, correlates, and antecedents. Austin: University of Texas Press.

Spence, J., Helmreich, R., \& Stapp, J. (1974). The personal attributes questionnaire: A measure of sex role stereotypes and masculinity and femininity. Journal Supplement Abstract Service Catalog of Selected Documents in Psychology, 4, 43.

Wallston, B. (1981). What are the questions in the psychology of women? A feminist approach to research. Psychology of Women Quarterly, 5, 597-617.

Walsh, J. A., Tomlinson-Keasey, C., \& Klieger, D. M. (1974). Acquisition of the social desirability response. Genetic Psychology Monographs, 89, 241-272.

Williams, J. E., Bennett, S. M., \& Best, D. L. (1975). Awareness and expression of sex stereotypes in young children. Developmental Psychology, 11, 635-642.

Zalk, S. R., \& Katz, P. A. (1978). Gender attitudes in children. Sex Roles, 4, 349-357. 